\title{
THE EFFECT OF PSYCHO-EDUCATIONAL INTERVENTION ON SELF EFFICACY AND QUALITY OF LIFE AMONG CAREGIVERS OF PATIENTS' WITH BIPOLAR DISORDER. ${ }^{1}$ Nesma Ahmed Kamel, ${ }^{2}$ Afaf Abdel-Hamid Abdel-Rahman, ${ }^{3}$ Osama Ahmed El-Boraie, ${ }^{4}$ Mona Ahmed El -Bilsha \\ 1\&4Psychiatric and Mental Health Nursing Department, Faculty of Nursing-Mansoura University 2Psychiatric and Mental Health Nursing Department, Faculty of Nursing- cairo University 3 Psychiatric Medicine Department, Faculty of Medicine - Mansoura University E-mail of the corresponding author: nesma ahmed kamel Dr_nesmaahmed@yahoo.com
}

\begin{abstract}
Background: Bipolar disorder (BD) is a chronic illness associated with severely debilitating symptoms that can have difficult effects on both patients and their caregivers. Bipolar disorders are a leading cause of disability worldwide, and people with these disorders experience a lower quality of life than the general population. Therefore, this study aimed at evaluating the effect of psycho-educational intervention on self- efficacy and quality of life among caregivers of patients of bipolar disorder. It has been carried out using a quasi-experimental research design. The subjects were constituted of 50 caregivers from in-patient Psychiatric Department of Mansoura University Hospital and were chosen according to inclusion criteria. The 50 caregivers were divided into ten groups, five caregivers in each group; each group attended ten sessions ( 3 sessions /week). In order to collect the necessary information for the study structure interview sheet was used to collect data. There was a statistical significant difference in mean scores of knowledge, selfefficacy, and quality of life before and post the intervention $(\mathrm{P}<0.05)$. Conclusion: it is concluded that, knowledge level, self- efficacy and quality of life of caregivers of patients of bipolar disorder improved significantly after psycho-educational intervention.

Keywords: Bipolar disorder; Family caregiver; Psycho-educational Intervention; Selfefficacy; Quality of life
\end{abstract}

\section{Introduction:}

Bipolar disorder (BD) is a leading cause of suffering for patients, but the burden it indirectly forced upon family members and caregivers. BD follows a chronic course that associated with $\mathrm{m}$ significant disability, distress, premature mortality, and marital problems ${ }^{[1]}$.

Bipolar disorder (BD) is a recurrent illness characterized by extreme fluctuation in mood and associated with severely symptoms that can have difficult effects on both patients and their caregivers. BD typically begins in adolescence or early adulthood and can have life-long adverse effects on the patient's physical and psychological health, occupational and educational functioning, and interpersonal relationships ${ }^{[2]}$.

Worldwide, BD is the 6th major cause of disability and has a lifetime prevalence of about $3 \%$ in the general population [3]. Prevalence of psychiatric co-morbidity among BD patients in Egypt was $20.3 \%$ while $18 \%$ had co-morbid substance abuse disorder and $2.3 \%$ had comorbid anxiety disorders ${ }^{[4]}$.

The disorders can lead to various psychosocial problems including poor 
QoL for the patients' families and become feeling stigmatized from caring of the patient ${ }^{[5]}$.

There is no doubt that family caregivers of BD patients suffer from high levels of burden and are at a high risk for developing emotional, social and behavioral disturbances. Also, family feels isolated and forced to sacrifice their social roles more often than is the case with other mental disorders ${ }^{[6]}$.

Families are generally vulnerable and unprepared to cope with the entire process of the illness and treatment ${ }^{[7]}$. For this reason, nurses and other healthcare professionals have a fundamental role to support patient/family and teaching them to identify stressors, understanding and recognizing them how to cope with problems as well as to intervene and decrease suffering, thus improve their readjustment ${ }^{[8]}$.

Hence, psychosocial interventions can reduce burden and psychological distress, as well as improve self efficacy for caregivers ${ }^{[9]}$.

Psycho educational intervention for caregivers can be beneficial both for those living with patients as well as for caregivers of patients who have greater social dysfunction through providing better conditions of understanding and comprehension about addressed pathology, as well as highlight and strengthen positive aspects of the patient ${ }^{[10]}$.

Therefore it is deemed necessary to conduct this study to assess the impact of psycho-educational intervention on selfefficacy and quality of life among family caregivers of patients with bipolar disorder.

\section{Aim of the study:}

To assess the impact of psycho educational intervention on self-efficacy and quality of life among family caregivers of patients with bipolar disorder.

\section{Design:}

Subjects and Method

A quasi experimental design was followed in this study.

Setting:

The study was carried out at the in-patient psychiatric department of Mansoura University Hospital.

Sample:

The number of the subject was calculated using the Epi- Info program using confidence coefficient $95 \%$, power averaging $80 \%$, error $5 \%$ with minimum sample size $=48$ increased to 50 caregivers to avoid any shortfall in the number of the study sample during the intervention.

This subject was chosen according to the following criteria:

\section{Inclusion criteria:}

1. Caregivers living with the patient in the same place.

2. Caregivers of patients with bipolar disorder (recent manic episode) according to DSM-IV-TR and the diagnosis was confirmed by two psychiatrists.

3. Caregivers willing to participate in the program of the study.

Tools for data collection:

1. Socio - Demographic Data Structured Interview Schedule: It was developed by the investigator to assess demographic data related to patients and their caregivers such as: sex, age, marital status, residence, occupation, years of education, degree of relatives and number of family members.

2. Knowledge questionnaire about bipolar disorder: It was developed by the researcher and supervisors after reviewing the literature to assess caregivers' knowledge about bipolar disorder (manic episode); definition, etiology, warning signs and symptoms, medications, side effect and importance of follow up....etc. 
QUALITY OF LIFE OF ELDERLY PATIENTS WITH etc...

3. Self- efficacy scale: ${ }^{11]}$ It was created originally by (Schwarzer and Jerusalem, 1995) to predict coping with daily hassles as well as adaptation after experiencing different kinds of stressful life events.

The tool is composed of 10 items that focuses on different skills and components of problem solving approaches. Responses are made on a 4 point scale, Responses to all 10 items are summed up to yield the final composite score, with arrange from 10 to 40 with mean cut of point equal 20 . Thus, the total self -efficacy score varies between 10 and 40. Higher score indicate higher self- efficacy. This tool was translated into Arabic language and validated by Radwan ${ }^{[12]}$.

\section{Quality of life scale: ${ }^{[13]}$}

This tool translated into Arabic by (world health organization, 1997) to assess the individual's perceptions according to their culture, value systems, their personal goals, standards and concerns.

It contains a total of 26 questions. To provide a broad and comprehensive assessment, 24 items contained from four domains. In addition, two items about the overall quality of life and general health have been included.

The mean score for each domain is calculated and then multiplied by 4 in order to transform the domain score into a scaled score of zero to 100 , with a higher score indicating a higher QOL. When transformed, each domain score is then comparable with the scores used in the original WHOQOL-BRIEF.

\section{Method:}

1- An official permission was obtained from the General Director of Psychiatric Department at Mansoura University Hospital after clarifying the purpose of the study.

2- Informed oral consent was obtained from the caregivers after explaining the aim of the study and assuring them about the confidentiality of the information.

3- Tool II was developed by the researcher after reviewing the relevant literature. It was tested for clarity, relevance, applicability, understanding, and ease for implementation by a jury in the related field of psychiatric medicine and nursing. The necessary modifications were applied according to experts' opinions.

4-A pilot study was carried out on $10 \%$ to ensure the clarity, applicability and feasibility of the study tools, and necessary modifications were done.

5- The researcher met with the caregivers, introduced herself and explained to them the aim of the study to obtain their consent to participate in the study and gain their cooperation and confidence.

6- The caregiver was interviewed individually before applying the planned program to collect the baseline data using all study tools.

7- The researcher started to fill-out the questionnaire from the caregivers through individual interviewing until reached the total number. The researcher read and explained each item to the caregivers and recorded their responses to each item. This interview took about 25 to 30 minute.

8-The objective of the program was to improve caregivers knowledge and understanding of illness and treatment in order to be more skillfully and efficiently capable of dealing with their patients. The program also provides these caregivers with a number of coping strategies to deal with their patients and to enhance their QOL.

9- The program was implemented for the caregivers, they were divided into (10) groups, five caregivers in each group. Each group attended 10 sessions (3 sessions /week). The researcher implemented the program for each group in scheduled times and days. To 
ensure exposure of all caregivers in the groups to the same content and learning experiences. The same content was provided using the same teaching methods, discussions and handouts.

10- The program was implemented through various teaching methods as short lectures, group discussions, brain storming, demonstration redemonstration, and role-play. The teaching media included power-point presentations and a handbook.

11- Each session was started by a summary about what was given through the previous session and the objectives of the new one to make sure that family caregivers recognize the program content, taking into consideration the use of simple language to suit the educational level of caregivers. Motivation and reinforcement techniques as praise and recognition were used during the session to enhance participation and learning.

12- The researcher designed an illustrative booklet in simple Arabic language to be distributed to caregivers.

\section{Evaluation phase}

- Immediately after the program. Evaluation was done to assess the impact of the program on the caregivers using tool II, tool III, and tool IV.

- After one and three months from implementation of the program, revaluation was done using the study tools.

\section{Ethical considerations}

- Anonymity, confidentiality and privacy of the caregivers were assured.

- Voluntary participation and right to refuse to participate in the study was emphasized to the subjects.

\section{Statistical analysis:}

Data were analyzed by SPSS version 21 . The normality of data was firstly tested by Shapiro-Wilk's test. Qualitative data were presented using numbers and percentage. Continuous variables were presented as mean \pm SD (standard deviation) if parametric data or median and interquartile range (IQR) if not. The Spearman's correlation calculates a coefficient, rs or $\rho$, which is a measure of the strength and direction of the association/relationship between two continuous or ordinal variables.

\section{Results:}

Table (1) shows the age of the patients and their caregivers and illustrated that median age of total patients are 30 of interquartile range (20.75-40.5) with mean and standard deviation $\mathbf{3 3 . 5 2}$ \pm 15.01. The median age of total caregivers 42 of interquartile range (36.5 50.09) with mean and standard deviation $\mathbf{4 1 . 7 2} \pm$ 11.16. No statistically significant difference in age distribution among the two ages of both patients and their caregivers.

Table (2) shows the sex of the studied patients and their caregivers, it appears from the table that 50 patients were 14 males (28\%) and 36 females (72\%) and their caregivers were 11 males $(22 \%)$ and 39 females $(78 \%)$. The table also illustrate that there was a statistically significant difference between sex of studied patients and their caregivers with the great majority of female patients $(94.4 \%)$ having female caregivers while male patients have $(64.3 \%)$ male caregivers and $(35.7 \%)$ female caregivers.

Table (3) shows socio-demographic data for studied caregivers. It appears from the table that, around $60 \%$ of the studied caregivers were in ages between 40 and less than 60. Concerning educational level, it was shown that $40 \%$ were illiterate while $30 \%$ were diploma and the rest of them were primary, preparatory, and secondary and college graduates. Speaking 
QUALITY OF LIFE OF ELDERLY PATIENTS WITH etc...

about marital status, majority of the studied caregivers were married and represented $(70 \%)$.

Concerning occupation, around $68 \%$ were housewives and $16 \%$ were workers. This table also illustrated that $60 \%$ of the studied caregivers were from rural areas, while $40 \%$ of them were from urban area. Regarding income satisfaction, it was found that $62 \%$ hadn't enough income while $38 \%$ of studied caregivers had enough income.

Regarding the relation to patient, it represented that $48 \%$ of the studied family caregivers were mothers, about $14 \%$ were daughters, $18 \%$ were sisters and brothers and $12 \%$ were fathers. Regards number of family member, it represented that $(50 \%)$ of studied caregivers have five to eight member while $42 \%$ have one to four member. A statistically significant difference was found in occupation and relation to patient of studied caregivers.

Table (4) shows total mean score of knowledge of caregivers before and after psycho-educational program, the mean score of knowledge for the studied caregivers were increased compared to pre program $(52.0 \pm 1.7)$ with median knowledge percent $(62.5 \%)$ immediately, while one and three months after the intervention, the knowledge mean scores of studied caregivers slightly decreased compared to immediately post (they equaled $43.2 \pm 9.6 \& 37.6 \pm 10.2$ respectively) with median knowledge percent $\quad(45.7 \% \quad \& \quad 42.6 \%$ respectively).There was statistical significant differences of studied caregivers' knowledge mean score between pre, immediately post, one month and three months after the program. $\mathrm{P} \leq 0.001$.

Table (5) shows the total selfefficacy mean scores of caregivers' pre, immediately post, one month and three months after program, the mean score of self-efficacy for the studied caregivers increased compared to pre program (33.5 \pm 2.4 ) with median and inter-quartile range 33.0 (32.0-35.0) immediately, while one and three months after intervention, self efficacy mean scores of studied caregivers slightly decreased compared to immediately post (they equaled $28.6 \pm 3.1$ $\& 26.3 \pm 2.9$ respectively) with median and inter-quartile range 28.0 (25. 5-30.0) \&

(24.0-28.0) respectively). There were statistical significant differences of studied caregivers self- efficacy mean score between pre, immediately post, one month and three months after the program. $\mathrm{P} \leq 0.001$.

Table (6) presents quality of life domains for studied caregivers' pre, immediately post, one and three months after program. Concerning physical domain, the mean scores for studied caregivers increased compared to pre program $(44.6 \pm 10.4)$ with median and interquartile range 44 (38-56) immediately post the program. In relation to psychological domain, the mean scores for studied caregivers increased compared to pre program (47 \pm 12.6) with median and inter-quartile range 44 (38 -56) immediately post the program. Speaking about social domain, the mean scores for studied caregivers increased compared to pre program $(43.5 \pm 13.1)$ with median and inter-quartile range 47 (31-50) immediately post the program.

Regarding environmental domain, the mean score of the studied caregivers increased compared to pre program (42.6 \pm 12.8 ) with median and inter-quartile range 44 (29-50) immediately post the program. Hence, A statistical significant difference was found between the quality of life domains mean score pre, immediately, one month and three months after intervention.

\section{Discussion:}

(BD) is a chronic illness associated with severely symptoms that can have difficult effects on both patients and their caregivers [14]. Families are involved in numerous conflicts and problems with 
these patients. There is no doubt that family member of patients experience a high level of burden and are at a high risk for developing emotional, social, and behavioral disorders [15].Hence, family caregivers needs psycho-educational program to reduce burden and enhance their QOL. The socio-demographic characteristics of the current study showed that two thirds of studied caregivers were in age group between 40-59 years old with mean and standard deviation of $41.72 \pm 1.116$. The majority of the studied family caregivers were females, married, housewives and low educational level. This is expected because females are responsible about caring of all family especially the sick member. These findings are congruent with the findings conducted by George, Sharma and Sreekumaran, (2015), [16], who reported that fifty two percent of the caregivers were females and belonged to the age group of 41-60 years. Most of them (64\%) were married and were housewives $(36 \%)$. In addition, the present study is consistent with AbdelAziz et al., (2011) [17], who mentioned that most of the caregivers in this study were mothers and/or females. In contrast, Ranjbar et al. (2015), [18], who reported that most of the participants were male and majority of them were employed.

The current study regarding the effect of the psycho-educational intervention on knowledge showed that there is a significant improvement of caregiver's knowledge mean score after intervention. This may be because many caregivers before interventions have insufficient awareness of the disease and are overwhelmed by a number of unanswered questions about how they should handle their distressed patients.

On the same line, this finding was supported by a recent study conducted in Egypt by Shata et al. (2017),[19], as there was a statistically significant improvement in the caregivers knowledge at post intervention.

Additionally, this finding is also in congruent with the findings of other studies carried out by Huis et al. (2015),[20], reported that the caregivers who received a psychoeducational programs had an increase in their knowledge about the illness and its treatment, as well as a reduction of the caregiver's subjective burden and disruptions in the their life.

Furthermore, the results of present study showed that knowledge level of the studied caregivers were slightly decreased at three months after intervention when compared the mean score at immediately post with three months after intervention. It may be related continuing need for education and decrease ability to retain information for long time.

Caregivers' self-efficacy (SE) is a significant factor that maintain the caregivers' physical and mental health and promote their healthy behaviors. It is also effective in empowering people for coping with different stressful situations as well as difficult and challenging tasks [21].

Therefore, the current study showed that there is a significant improvement of caregiver's self- efficacy after psychoeducational program. It could be explained that, combining information about the illness and its treatment with education in communication skills and problem solving techniques, supports the caregivers in understanding and accepting the psychiatric patients, improving the ability to make decision and to manage effectively the with demands of care. Similarly, Yildirim et al. (2014), [22], stated that education program is effective in reducing the pressures imposed on the family as well as increase their selfefficacy. Additionally, Casado and Sacco. (2012), [23], mentioned that interventions can be more effective in building family 
QUALITY OF LIFE OF ELDERLY PATIENTS WITH etc...

support, improving family agreement in care giving, and increasing caregivers' self- efficacy in their care giving role.

Quality of life (QOL) is the most important issues of the families with psychiatric patients, especially those with bipolar disorder. Actually, QOL is an individual's specific perception of life satisfaction, physical health, social and family health, and mental health.

Findings of the present study illustrated that increase total mean score of four domains of quality of life (physical, psychological, social and environmental) especially psychological domain after psycho-educational program immediately, one month and three months after intervention and there was a statistically significant difference between all quality of life domains score over time. This may be due to giving information and support in addition to willingness and motivation to learn for effective coping with their patients and able to cope with a considerable amount of the caring roles and responsibilities.

The present findings are in agreement with Zahra, Fateme, and Mohsen .(2014) ,[24], stated that increase in the mean scores of quality of life immediately and one month after the intervention in the domains of physical health, mental health, and social communications in the studied caregivers. Similarly, the study conducted by Taleghani et al. (2012), [25], who mentioned that the differences in subscales were significant in two phases of intervention in Tehran.

In this respect, the study conducted in Egypt by Soliman, Mahdy and Fouad. (2018) ,[26], reported that there is statistically significant difference between all four domains of quality of life among caregivers who received psycho-education measured by WHO QoL scale. With higher score, number of relapses diminishes, need for hospitalization diminishes and the financial burden on caregivers diminishes too. The present study demonstrated that caregivers after psycho-educational intervention had improvement on their quality of life immediately, one month and three months after intervention.

Moreover, the results conducted in Iran demonstrated that family intervention could improve psychological welfare of the family members and could improve QOL in the caregivers immediately after and one month after the intervention [27]. Therefore, it could be said that the combination of psychological and educational intervention like the programs conducted in the present study could satisfy many needs of those caregivers and will empower them to improve their self-efficacy and quality of life.

\section{Conclusion:}

Based on the findings of the present study, it can be concluded that knowledge level, self-efficacy and quality of life of caregivers of patients with bipolar disorder improved significantly after psychoeducational intervention. Also, there is a relationship between socio-demograpgic characteristics of caregivers and their knowledge level, self- efficacy and quality of life.

\section{Recommendation:}

1. Assessing the family's needs in caring for clients with mental illness and providing psychoeducational program is necessary to enhance family members' understanding and expectations of the illness.

2. Enhance family orientation and awareness about available services and resources are helpful to sustain family care giving.

3. All caregivers of patients with bipolar disorder should be counseled and encouraged to participate in educational 
programs to understand unnecessary behavioral changes and to reduce feeling of stigma to improve their self- efficacy and quality of life.

4. Integration of knowledge of how to support family caregivers for persons with mental disorders and curriculum about education of healthcare professionals in general, and for the psychiatric team, in particular will improve mental health practice.

5. The following strategies should be implemented for family caregivers such as awareness about importance of follow up after patient discharge; training sessions about bipolar disorder; and psychosocial support to help families cope with the destructive effects of disorder and aggression issues.

6. Conduct a study with large sample size and longer follow up to assess the effect of a group psycho-educational program not only on the QOL of families of patients with bipolar disorders but also on the families with patients of other psychiatric disorders.

\section{Acknowledgements:}

We would like to thank all the caregivers who participated in the study and staff of the psychiatric department at Mansoura Hospital for their help and cooperation during the study period and appreciate the great efforts of the supervisors in this work.

Table (1): Age of the studied patients and their caregivers:

\begin{tabular}{|c|c|c|c|c|}
\hline \multirow{2}{*}{ Group } & \multicolumn{3}{|l|}{ Age (years) } & \multirow[b]{2}{*}{$\mathbf{p}$} \\
\hline & Total & Male & Female & \\
\hline $\begin{array}{l}\text { Patients } \\
\text { Median } \\
\text { (IQR) }\end{array}$ & $\begin{array}{l}30(20.75-40.5) \\
16-70\end{array}$ & $\begin{array}{l}27(20.0-34.25) \\
16-61\end{array}$ & $\begin{array}{l}(22.0-43.5), \\
16-70\end{array}$ & 0.112 \\
\hline \multicolumn{5}{|c|}{ Mean \pm SD 33.52 \pm 15.01} \\
\hline $\begin{array}{l}\text { Caregivers } \\
\text { Median } \\
\text { (IQR) }\end{array}$ & $\begin{array}{l}42(36.5-50.09) \\
20-62\end{array}$ & $\begin{array}{l}42(35.0-49.0), \\
27-62\end{array}$ & $\begin{array}{l}45(37.0-50.0), \\
20-60\end{array}$ & 0.760 \\
\hline \multicolumn{5}{|c|}{ Mean \pm SD 41.72 \pm 11.16} \\
\hline
\end{tabular}

Table (2): Sex of the studied patients and their caregivers:

\begin{tabular}{|l|l|l|l|l|}
\hline \multirow{2}{*}{ Patients' sex } & Caregivers' sex & \multirow{2}{*}{$\chi^{\mathbf{2}}$} & \multirow{2}{*}{$\mathbf{p}$} \\
\cline { 2 - 3 } & Male & Female & \multirow{2}{*}{20.261} & \multirow{2}{*}{$\mathbf{0 . 0 0 0 5 *}$} \\
\hline Male & $9(64.3 \%)$ & $5(35.7 \%)$ & $34(94.4 \%)$ & \\
\hline
\end{tabular}

*Significant, at $\mathrm{P} \leq 0.05$

Data are expressed as count (percent), $\mathrm{p}$ by Fisher's exact test. 
Table (3): Socio-demographic data for studied caregivers $(n=50)$ :

\begin{tabular}{|c|c|c|c|c|}
\hline Parameter & Total & Male & Female & $\mathbf{p}$ \\
\hline $\begin{array}{l}\text { Age } \\
20-39 \\
40-59 \\
60 \text { and more }\end{array}$ & $\begin{array}{l}18(36 \%) \\
30(60 \%) \\
2(4 \%)\end{array}$ & $\begin{array}{l}3 \\
7 \\
1\end{array}$ & $\begin{array}{l}15 \\
23 \\
1\end{array}$ & 0.122 \\
\hline $\begin{array}{l}\text { Education level: } \\
\text { Illiterate: } \\
\text { Read \& write: } \\
\text { Primary: } \\
\text { Preparatory: } \\
\text { Secondary: } \\
\text { Diploma: } \\
\text { University level: }\end{array}$ & $\begin{array}{l}20(40 \%) \\
3(6 \%) \\
3(6 \%) \\
4(8 \%) \\
2(4 \%) \\
15(30 \%) \\
3(6 \%)\end{array}$ & $\begin{array}{l}3 \\
1 \\
0 \\
2 \\
2 \\
2 \\
1\end{array}$ & $\begin{array}{l}17 \\
2 \\
3 \\
2 \\
0 \\
13 \\
2\end{array}$ & 0.076 \\
\hline $\begin{array}{l}\text { Marital status: } \\
\text { Single: } \\
\text { Married: } \\
\text { Divorced: } \\
\text { Widow: }\end{array}$ & $\begin{array}{l}7(14 \%) \\
35(70 \%) \\
4(8 \%) \\
4(8 \%)\end{array}$ & $\begin{array}{l}3 \\
8 \\
0 \\
0\end{array}$ & $\begin{array}{l}4 \\
27 \\
4 \\
4\end{array}$ & 0.257 \\
\hline $\begin{array}{l}\text { Occupation: } \\
\text { Employee: } \\
\text { Worker: } \\
\text { Housewife: } \\
\text { Farmer: }\end{array}$ & $\begin{array}{l}6(12 \%) \\
8(16 \%) \\
34(68 \%) \\
2(4 \%)\end{array}$ & $\begin{array}{l}4 \\
5 \\
0 \\
2\end{array}$ & $\begin{array}{l}2 \\
3 \\
34 \\
0\end{array}$ & $<0.0005 *$ \\
\hline $\begin{array}{l}\text { Residency: } \\
\text { Urban: } \\
\text { Rural: }\end{array}$ & $\begin{array}{l}20(40 \%) \\
30(60 \%)\end{array}$ & $\begin{array}{l}3 \\
8\end{array}$ & $\begin{array}{l}17 \\
22\end{array}$ & 0.329 \\
\hline $\begin{array}{l}\text { Income satisfaction: } \\
\text { Not enough: } \\
\text { Enough: } \\
\end{array}$ & $\begin{array}{l}31(62 \%) \\
19(38 \%)\end{array}$ & $\begin{array}{l}8 \\
3 \\
\end{array}$ & $\begin{array}{l}23 \\
16 \\
\end{array}$ & 0.407 \\
\hline $\begin{array}{l}\text { Relation to patient: } \\
\text { Mother: } \\
\text { Father: } \\
\text { Partner: } \\
\text { Sister/brother: } \\
\text { Daughter: }\end{array}$ & $\begin{array}{l}24(48 \%) \\
6(12 \%) \\
4(8 \%) \\
9(18 \%) \\
7(14 \%)\end{array}$ & $\begin{array}{l}0 \\
6 \\
1 \\
4 \\
0\end{array}$ & $\begin{array}{l}24 \\
0 \\
3 \\
5 \\
7\end{array}$ & $<0.0005^{*}$ \\
\hline $\begin{array}{l}\text { Number of family members: } \\
\text { One-four: } \\
\text { Five-eight: } \\
\text { >Eight: }\end{array}$ & $\begin{array}{l}21(42 \%) \\
25(50 \%) \\
4(8 \%)\end{array}$ & $\begin{array}{l}4 \\
5 \\
2\end{array}$ & $\begin{array}{l}17 \\
20 \\
2\end{array}$ & 0.369 \\
\hline
\end{tabular}


Table (4): Total knowledge mean score of caregivers before and after psychoeducational program $(n=50)$

\begin{tabular}{|c|c|c|c|c|c|}
\hline Parameter & Baseline & Immediate & One month & $\begin{array}{c}\text { Three } \\
\text { months }\end{array}$ & $\mathbf{p}$ \\
\hline Mean \pm SD & $24.0 \pm 6.1$ & $52.0 \pm 1.7$ & $43.2 \pm 9.6$ & $37.6 \pm 10.2$ & \multirow{4}{*}{$<0.005 *$} \\
\hline $\begin{array}{l}\text { Median } \\
\text { (IQR) }\end{array}$ & $\begin{array}{c}23.5(19.75- \\
28.0)\end{array}$ & $\begin{array}{l}52.0(52.0- \\
60.0)\end{array}$ & $\begin{array}{c}37.0(34.75- \\
44.0)\end{array}$ & $\begin{array}{c}34.5(30.0- \\
41.0)\end{array}$ & \\
\hline $\begin{array}{l}\text { Median } \\
\text { knowledge } \\
\text { percent }\end{array}$ & $29 \%$ & $62.5 \%$ & $45.7 \%$ & $42.6 \%$ & \\
\hline $\begin{array}{l}\text { Pair wise } \\
\text { comparisons }\end{array}$ & $\mathrm{C}$ & B & A & A & \\
\hline
\end{tabular}

P by Friedman's test. In pair wise comparisons, those with similar capital letters are not statistically significantly different while those with different capital letters are statistically significantly different.

Table (5): Total Self-efficacy mean score for caregivers before and after psychoeducational program $(\mathbf{n}=50)$ :

\begin{tabular}{|c|c|c|c|c|c|}
\hline Parameter & Baseline & Immediate & One month & $\begin{array}{c}\text { Three } \\
\text { months }\end{array}$ & p \\
\hline Mean \pm SD & $17.5 \pm 3.3$ & $33.5 \pm 2.4$ & $28.6 \pm 3.1$ & $26.3 \pm 2.9$ & \multirow{3}{*}{$<0.0005^{*}$} \\
\hline $\begin{array}{l}\text { Median } \\
\text { (IQR) }\end{array}$ & $\begin{array}{c}18.0(15.0- \\
20.0)\end{array}$ & $\begin{array}{c}33.0(32.0- \\
35.0)\end{array}$ & $\begin{array}{c}28.0(25.5- \\
30.0)\end{array}$ & $\begin{array}{c}27.0(24.0- \\
28.0)\end{array}$ & \\
\hline $\begin{array}{l}\text { Pair wise } \\
\text { comparisons }\end{array}$ & $\mathbf{A}$ & B & $\mathrm{C}$ & $\mathrm{C}$ & \\
\hline
\end{tabular}

*Significant, at $\mathrm{P} \leq 0.05$

P by Friedman's test. In pair wise comparisons, those with similar capital letters are not statistically significantly different while those with different capital letters are statistically significantly different. 
QUALITY OF LIFE OF ELDERLY PATIENTS WITH etc...

Table (6): Quality of life domains' mean scores for caregivers before and after psychoeducational program $(n=50)$ :

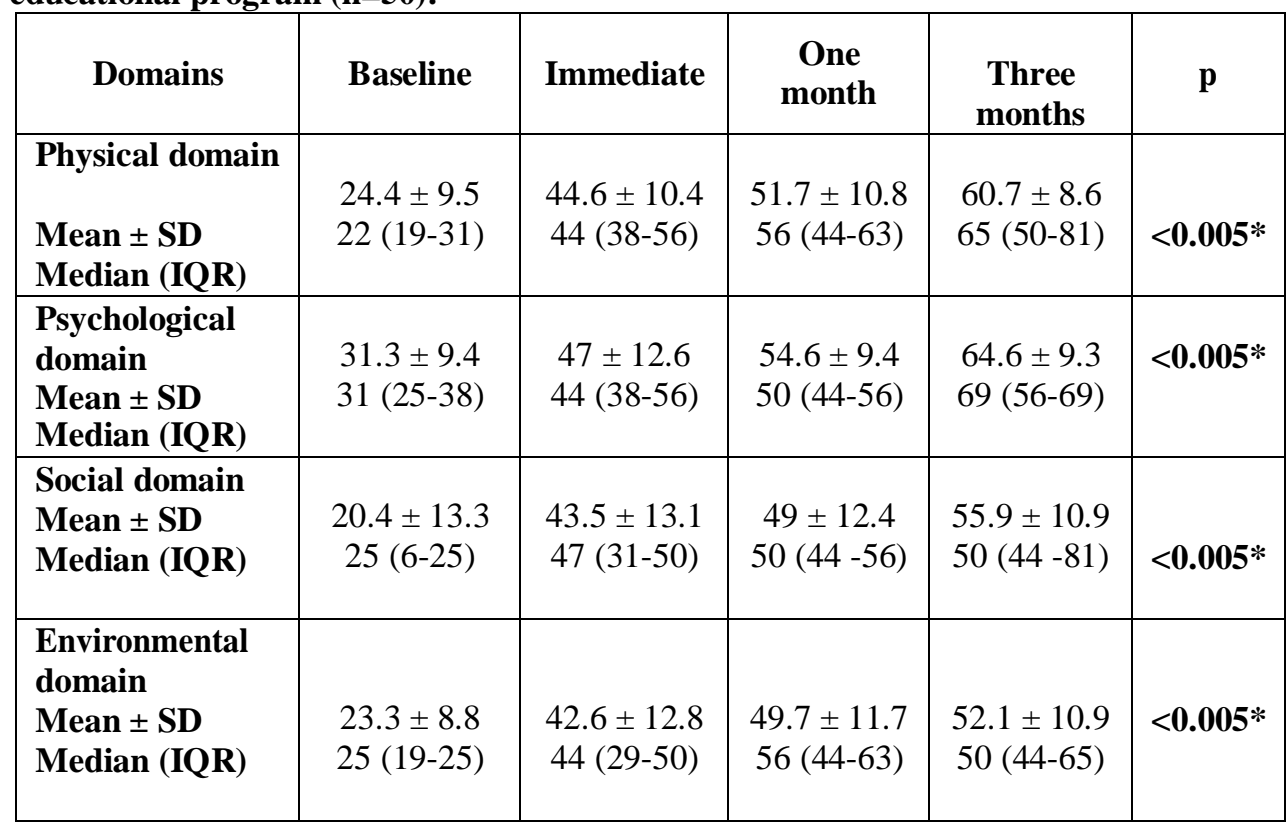

Data were expressed as mean \pm SD in the first row, median (IQR) in the second row and $\mathrm{P}$ value by Friedman's test.

\section{References:}

1. Pompili, M., Harnic, D., Gonda, X., Forte, A., Dominici, G., Innamorati, M., Fountoulakis, K.N., Serafini, G., Sher, L., Janiri, L., Rihmer, Z., Amore, M., Girardi, P. (2014). Impact of living with bipolar patients: making sense of caregivers' burden. World Journal of Psychiatry, 22(1), 112.

2. American Psychiatry Association. (2013). Diagnostic and Statistical Manual of Mental Disorders (5th ed.). Arlington: American Psychiatric Publishing Virginia, 123-154. ISBN 089042-555-8.

3. Schmitt, A., Malchow, B., Hasan, A., Falkai P. (2014). The impact of environmental factors in severe psychiatric disorders". Front Neuroscience. 8 (19).
4. Asaad,T.,Okasha, T.,Ramy, H.,Fekry,M.,Nivert,Z.(2014).Correla tes of psychiatric co-morbidity in a sample of Egyptianpatientswithbipolar disorder,Journal of affective disorder, institute psychiatry,cairouniversity,Egypt,166, 347-352.

5. Ssebunnya, J., Kigozi, F., Lund, C., Kizza, D., Okello, E.(2009).International Healthand Stakeholder perceptions of mental health stigma and poverty.BioMedCentral.International Health and Human Rights, 9(1), 1-9. 
6. Duffy, A., Horrocks, J., Doucette, S., Keown-Stoneman, C., Grof, P., Andreazza, A.et al.(2014). Immunological and neurotrophic markers of risk status and illness development in high-risk youth: understanding the neurobiological underpinnings of bipolar disorder. International Journal of Bipolar Disorders, 2(1), 24.

7. Kate, N., Grover, S., Kulhara, P., Nehra,R.(2013). Relationship of caregiver burden with coping strategies, social support, psychological morbidity, and quality of life in the caregivers of schizophrenia. Sian Journal of Psychiatry, 6(5), 380-8.

8. Caqueo-Urízar, A., MirandaCastillo, C., LemosGiráldez, S., Lee Maturana, S.L., Ramírez Pérez, M., Mascayano Tapia, F.(2014). An updated review on burden on caregivers of schizophrenia patients. Psicothema journal, 26(2), 235-43.

9. Brodaty, H.,\&Arasaratnam, C.(2012). Meta-analysis of nonpharmacological interventions for neuropsychiatric symptoms of dementia. American Journal of Psychiatry, 169, 946- 953.

10. Chessick, C. A., Perlick, D. A., Miklowitz, D. J., Dickinson, L.M., Allen, M. H., Morris, C. D., Ostacher, M. (2009).Suicidal ideation and depressive symptoms among bipolarpatients as predictors of the health and well-being of caregivers.Bipolar Disorders, 11, 876-884.

11. Schwarzer R. \& Jerusalem M. (1995): Generalized Self -Efficacy scale. International Journal in health psychology: Causal and control beliefs: $35-37$.

12. Radwan, G. (1997). Self -efficacy expectation and theoretical construction, Journal of social affairs, 55(14), 25-55.

13. The WHOQOL Group. (1995). The development of the World Health Organization quality of life assessment instrument(the WHOQOL). In J. Orley and W. Kuyken (Eds) Quality of Life Assessment: International Perspectives. Heidelberg:Springer Verlag.

14. Mansfield, K., Dealy, A.\&Keitner, I. (2012).Family interventions for bipolardisorder: a review of the literature, Neuropsychiatry,2(3), available www.futuremedicine.com.

15. Maoz, H., Goldstein, T., Goldstein, B.I., Axelson, D.A., Fan, J., Hickey, M.B., et al.(2014). The effects of parental mood on reports of their children's psychopathology. Journal of American Academy Child and Adolescence Psychiatry, 53(1), 111122.

16. George, L., Sharma, P., Sreekumaran, N. (2015): Effect of psycho-education on Knowledge, Attitude and Burden among caregivers of persons with Bipolar Disorder - Randomized Controlled Trial.International Journal of Advanced Research, 3(7), 199-208.

17. Abdel-Aziz, E., Shaheen, M., and Abdel-kader, N. (2011). Impact of psycho educational program on burdens among family caregivers of schizophrenic patients, Mental health Nursing, Faculty of Nursing, Cairo University, Cairo, Egypt; 7(12),pp:822-830. (ISSN: 1545-1003). http://www.americanscience.org. 
18. Ranjbar, F., Rahmani, F., Ebrahimi, H., Hosseinzadeh, M. (2015). The Effects of Group Psychoeducational Programme on Attitude toward Mental Illness in Families of Patients with Schizophrenia.Journal of Caring Sciences, 4(3), 243-251.

19. Shata, Z., Amin,M., El-Kady, H., and Abu-Nazel,

M.(2017).Efficacy of a multicomponent psychosocial intervention program for caregivers of persons living with neurocognitive disorders, Alexandria, Egypt: A randomized controlled trial.Medicine; 7(2): 54-63.

20. Huis, V., Verkaik, R., Mistiaen, P., Meijel, B., Francke, A.L. (2015). The effectiveness of interventions in supporting self-management of informal caregivers of people with dementia; a systematic metareview. Biomed Central Geriatric journal,15:147.

21. Savundra,M.Y., \&Brintnall, M.(2010).Testing self-efficacy as a pathway that supports self-care among family caregivers in a psychoeducational intervention. Journal of Family Social Work, 13:149-62.

22. Yildirim,

A, Buzlu,

S., Hacıhasanoğlu, R., Camcioğlu, T.H., Erdiman,

S., Ekinci, M.(2014).The Effect of Family-toFamily Support Programs Provided for Families of Schizophrenic Patients on Information about Illness, Family Burden and Self-Efficacy. Turkish Journal of Psychiatry, 25(1),31-7.
23. Casado, B., \& Sacco, $\quad$ P. (2012). Correlates of caregiver burden among family caregivers of older Korean Americans. The Journals of Gerontology, Series B: Psychological Sciences and Social Sciences, 67(3), 331-336.

24. Zahra, G., Fateme, D., and Mohsen Y. (2014). The effect of group psychoeducational program on quality of life in families of patients with mooddisorders.Iranian Journal Nursing and Midwifery Research, 19(1): 50-55.

25. Taleghani, F., Babazadeh, S.H., Mosavi, S., Tavazohi, H. (2012). The effects of peer support group on promoting quality of life in patients with breast cancer. Iranian Journal of Nursing and Midwifery Research,17(2),125-30.

26. Soliman, E., Mahdy, R., Fouad, H.(2018):Impact of psycho-education program on quality of life of schizophrenic patients and their caregivers.Psychiatry Department, Zagazig University, Zagazig, Egyptian journal of psychiatry,39(1), 35-41.

Sharif, F., Mahmoudi, A., AlaviShooshtari, A., Vossoughi,M.(2016): The Effect of Family-Centered Psycho-Education on Mental Health and Quality of Life of Families of Adolescents with Bipolar MoodDisorder: A Randomized Controlled Clinical Trial. International Journal of Community Based Nursing and Midwifery,4(3), 229-238. 